\title{
Influence of cysteine adsorption on the performance of CdSe quantum dots sensitized solar cells
}

\author{
Xueqing $\mathrm{Xu}^{\mathrm{a}, *}$, Sixto Giménez ${ }^{\mathrm{b}}$, Iván Mora-Seró ${ }^{\mathrm{b}, *}$, Antonio Abate ${ }^{\mathrm{b}}$, Juan Bisquert ${ }^{\mathrm{b}}$, Gang Xu $^{\mathrm{a}}$ \\ a Guangzhou Institute of Energy Conversion, Renewable Energy and Gas Hydrate Key Laboratory of Chinese Academy of Sciences, Guangzhou 510640, China \\ b Photovoltaic and Optoelectronic Devices Group, Departament de Física, Universitat Jaume I, Castelló 12071, Spain
}

\section{A R T I C L E I N F O}

\section{Article history:}

Received 20 January 2010

Received in revised form 23 March 2010

Accepted 18 July 2010

\section{Keywords:}

Cysteine

CdSe quantum dots

$\mathrm{TiO}_{2}$ electrode

Surfaces

Solar cells

\begin{abstract}
A B S T R A C T
The surface of mesoporous $\mathrm{TiO}_{2}$ electrodes has been functionalized with cysteine using different solutions for the subsequent attachment of colloidal CdSe QDs solved in toluene. The adsorption behavior of both cysteine and $\mathrm{CdSe}$ QDs on the $\mathrm{TiO}_{2}$ nanoparticles has been investigated by Attenuated Total ReflectanceFourier Transform Infrared (ATR-FTIR) Spectroscopy. The photoelectrochemical properties of the CdSe QDs sensitized $\mathrm{TiO}_{2}$ electrode have been characterized by using UV-vis spectroscopy, photocurrentpotential measurement, open-circuit voltage decay, and cyclic voltammetry. It is found that the amount of adsorbed cysteine becomes excessive when highly concentrated aqueous solutions were adopted instead of toluene solutions, leading to a blocking for the diffusion and adsorption of the CdSe QDs. This is translated into a decrease of light harvesting and short circuit current $\left(J_{s c}\right)$ in the solar cell devices. On the other hand, it is suggested that the large amount of adsorbed cysteine on the surface of the $\mathrm{TiO}_{2}$ electrode could reduce the electron recombination at the interface between the $\mathrm{TiO}_{2}$ electrode and the electrolyte. As a consequence, the charge transfer resistance and fill factor became larger, and the electron lifetime became longer.
\end{abstract}

(C) 2010 Elsevier B.V. All rights reserved.

\section{Introduction}

Organic dye-sensitized Nano-crystalline $\mathrm{TiO}_{2}$ solar cells (DSSCs) have attracted significant attentions as low-cost photovoltaic devices [1,2]. As inorganic light absorbers, semiconductor quantum dots (QDs) have drawn great interest as light sensitizers in QDSSCs for the following reasons: Firstly, its tunable band edge offers new opportunities for harvesting light energy in most of the visible region of the solar spectrum [3]. In addition, QDs exhibit a larger extinction coefficient than organic dyes [4]. It has been also suggested that QDs allow to utilize hot electrons or generate multiple charge carriers with a single photon [5,6]. Although the conversion efficiencies of QDSSCs are in this moment far away of the efficiencies of DSSCs, in the last 2 years the maximum reported efficiencies have increased in a factor 2-3, highlighting the enormous potentiality of this kind of solar device. Many authors consider QDSSCs as analogous to DSSCs, but this is not completely true. For the use of QDs as light absorber it is necessary to take into account the specific properties of QDs (role of surface states, stability, preparation, attaching mode to $\mathrm{TiO}_{2}, \ldots$ ). In this sense the study of these specific properties of QDSSCs is very important in order to optimize

\footnotetext{
* Corresponding authors.

E-mail addresses: xuxq@ms.giec.ac.cn (X.Xu), sero@fca.uji.es, sero@exp.uji.es (I. Mora-Seró).
}

their performance. In this work we will focus in the role of the liker molecule used to attach colloidal QD to $\mathrm{TiO}_{2}$ surface, showing that not only the linker molecule (we compare cysteine and MPA) but also the treatment (we compare adsorption from water and from toluene solutions) carried out to attach these molecules to $\mathrm{TiO}_{2}$ influences the final performance of QDSSCs.

In order to study these properties colloidal CdSe QDs have been used as light sensitizers. CdSe QDs have received particular attention due to their relatively easy synthesis and also because of its suitable bandgap ( $1.7 \mathrm{eV}$ for bulk material). The properties of the QDs can be carefully tailored in the colloidal synthesis, but in this case is necessary to develop a method to attach the colloidal QDs to the semiconductor nanostructured matrix. To assemble the CdSe colloidal QDs onto the large bandgap semiconductors such as $\mathrm{TiO}_{2}, \mathrm{ZnO}$, or $\mathrm{SnO}_{2}$, bifunctional linkers of HS-R-COOH, such as mercaptopropionic acid (MPA), thiolacetic acid (TAA), mercaptohexadecanoic acid (MDA), and thioglycolic acid (TGA) have been adopted [7,8]. Recently, Mora-Seró et al. have shown that the incident photon to charge carrier generation efficiency (IPCE) can be improved by a factor of 5-6 if cysteine is used as a linker instead of MPA [8]. In this study, different cysteine solutions (varying both solvent and concentration) were adopted to improve the linkage between the $\mathrm{TiO}_{2}$ electrodes and CdSe QDs. The light harvesting performance and the photoelectrochemical properties of the CdSe QDs sensitized solar cells (QDSSCs) previously functionalized by different cysteine solutions have been investigated. 
Table 1

Description of the different cysteine solutions employed in the present study and MPA solution employed as a reference.

\begin{tabular}{llll}
\hline Solvent & $\begin{array}{l}\text { Concentration } \\
\left(\mathrm{mol} \mathrm{l}^{-1}\right)\end{array}$ & Dipping time & Temperature $\left({ }^{\circ} \mathrm{C}\right)$ \\
\hline Toluene & $\begin{array}{l}\text { Saturation (ca. } \\
0.022)\end{array}$ & $12 \mathrm{~h}$ to 7 days & 25 \\
$\mathrm{H}_{2} \mathrm{O}$ & 0.4 & $1 \mathrm{~h}$ & 70 \\
MPA in ACN & 1.1 & $12 \mathrm{~h}$ & 25 \\
\hline
\end{tabular}

\section{Experimental}

\subsection{Preparation of CdSe QDS}

CdSe QDs were prepared by a solvothermal method as reported by Wang et al. [9]. Briefly, selenium reacted with cadmium myristate in toluene in the presence of oleic acid and trioctylphosphine (TOP). The reaction took place at $180^{\circ} \mathrm{C}$ in an autoclave for $15 \mathrm{~h}$. Finally, the obtained CdSe QDs solutions were purified by precipitation in ethanol, isolation by centrifugation and decantation for three times.

\subsection{Preparation of $\mathrm{CdSe} \mathrm{QDs}$ sensitized $\mathrm{TiO}_{2}$ electrodes}

Dyesol DSL $18 \mathrm{NR}-\mathrm{AO} \mathrm{TiO}_{2}$ paste (20-400 nm particle size) has been spread onto bare $\mathrm{SnO}_{2}$ : F(FTO) glass substrates previously coated with a compact $\mathrm{TiO}_{2}$ layer in the thickness of about $100 \mathrm{~nm}$ by spray pyrolysis. After being heated at $120^{\circ} \mathrm{C}$ for $15 \mathrm{~min}$, the $\mathrm{TiO}_{2}$ electrodes were sintered at $450{ }^{\circ} \mathrm{C}$ for $30 \mathrm{~min}$. The thickness of the $\mathrm{TiO}_{2}$ films was approximately $10 \mu \mathrm{m}$ as measured by a Dektak Profilometer from Veeco. After heating, the $\mathrm{TiO}_{2}$ electrodes were immersed into the cysteine solution. Two different solvents were tested (water and toluene) as shown in Table 1. Subsequently, the substrates were rinsed with the correspondent solvent. As a reference, MPA in acetonitrile solution was also studied. Finally, the modified electrodes were dipped into the CdSe toluene solutions for at least $24 \mathrm{~h}$.

\subsection{Fabrication of CdSe QDs sensitized solar cells}

The CdSe QDSSCs were prepared by assembling a QDs sensitized $\mathrm{TiO}_{2}$ electrode with a Pt counter electrode by using a thermoplastic frame (Dupont ${ }^{\mathrm{TM}}$ Surlyn ${ }^{\circledR} 1702$, thickness $25 \mu \mathrm{m}$ ). The $\mathrm{Na}_{2} \mathrm{~S}_{x}$ redox electrolyte consisted of $1 \mathrm{M} \mathrm{Na}_{2} \mathrm{~S}, 1 \mathrm{MS}$, and $0.1 \mathrm{M}$ $\mathrm{NaOH}$ in Milli-Q ultrapure water.

\subsection{Optical and electrochemical measurements}

The UV-vis reflectance spectra of the samples have been carried out with a Shimadzu UV-2401 UV-vis spectrophotometer. The Attenuated Total ReflectanceFourier Transform Infrared (ATR-FTIR) spectra of the surface of the $\mathrm{TiO}_{2}$ films have been obtained by a Nicolet/Nexus 670 FT-IR spectrophotometer. The $\mathrm{TiO}_{2}$ films $(10 \mu \mathrm{m}$ in thickness) coated with cysteine or CdSe QDs were put onto the ZnSe prism to collect the ray reflected from the surface of the films. The ATR-FTIR spectra were obtained in air for dry films. Photocurrent-potential, open-circuit voltage decay and cyclic voltammetry curves were obtained with a FRA equipped Autolab PGSTAT-30 electrochemical work station. A solar simulator equipped with a $1000 \mathrm{~W}$ ozone-free xenon lamp and an AM 1.5 G filter (Oriel) has been used for illumination. The light intensity was adjusted with an NREL calibrated Si solar cell with a KG-5 filter to 1 sunlight intensity $\left(100 \mathrm{~mW} \mathrm{~cm}^{-2}\right)$.

\section{Results and discussion}

The solubility of cysteine in toluene is very low (less than $0.022 \mathrm{moll}^{-1}$ ) as it has been experimentally checked. In order to increase the amount of adsorbed cysteine and consequently that of $\mathrm{CdSe}$ QDs onto the $\mathrm{TiO}_{2}$ surface, a $0.4 \mathrm{moll}^{-1}$ aqueous cysteine solution was investigated. Fig. 1 shows the UV-vis reflectance spectra of the CdSe QDs sensitized $\mathrm{TiO}_{2}$ electrodes for different linker solutions accordingly to Table 1 . For cysteine in toluene, in our experiments a dipping time from $12 \mathrm{~h}$ to 7 days has been investigated (at room temperature). We have checked that in this time range, the dipping time has not any influence on the adsorption of CdSe quantum dots. However, for the ATR-IR measurement, the sample with the dipping time of 7 days has been used. For the cysteine in water, in order to enhance the diffusion of cysteine into the pores of the $\mathrm{TiO}_{2}$ electrodes, and to decrease the dipping time of the $\mathrm{TiO}_{2}$ electrode in water which may has some extra influences to the $\mathrm{TiO}_{2}$ films, a temperature of $70^{\circ} \mathrm{C}$ and the dipping

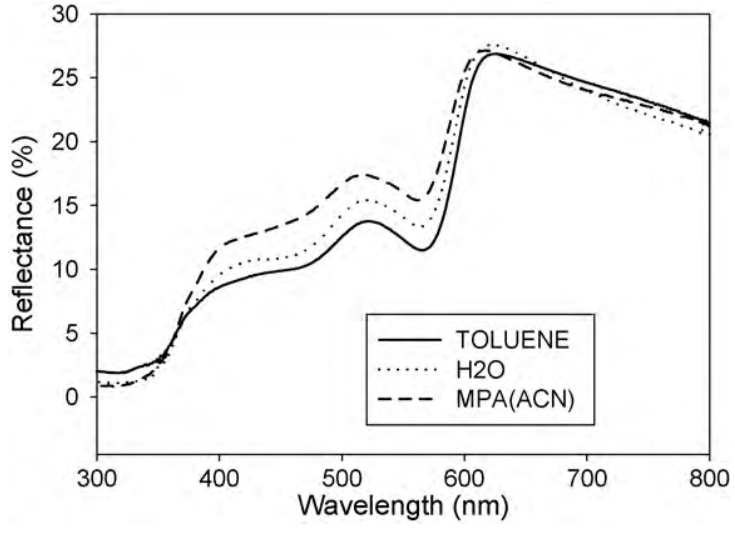

Fig. 1. The UV-vis reflectance spectra of $\mathrm{CdSe}$ sensitized $\mathrm{TiO}_{2}$ electrodes for the different linker solutions.

time of $1 \mathrm{~h}$ has been used. The absorption peak around $564 \mathrm{~nm}$ is due to the first excitonic absorption of $2.8 \mathrm{~nm}$ CdSe QDs [8]. The absorbance of the QDs sensitized $\mathrm{TiO}_{2}$ electrode at $564 \mathrm{~nm}$ became slightly weaker when the aqueous cysteine solutions were adopted, indicating a lower amount of adsorbed CdSe QDs. This is believed to be caused by an excess of adsorbed cysteine on the surface of the $\mathrm{TiO}_{2}$ nanoparticles leading to a partial blocking of the nanopores. In comparison with MPA, the absorbance of the QDs sensitized $\mathrm{TiO}_{2}$ electrode at $564 \mathrm{~nm}$ became higher when the cysteine solutions were used, as it has been recently reported [8].

Fig. 2 shows the ATR-FTIR spectra of the $\mathrm{TiO}_{2}$ films, the cysteine functionalized $\mathrm{TiO}_{2}$ films using both solutions and the CdSe sensitized $\mathrm{TiO}_{2}$ films (cysteine in toluene solution was used). The vibration band assignments of the spectra are shown in Table 2 [10]. Comparing the $\mathrm{TiO}_{2}$ films functionalized with both cysteine solutions, the characteristic vibration modes of the IR curves are almost identical. However, the intensities of the adsorption peaks were stronger for the aqueous solution. Additionally, the - $\mathrm{SH}$ and $-\mathrm{COOH}$ groups could be observed only for the aqueous solution. This means that the amount of adsorbed cysteine on $\mathrm{TiO}_{2}$ is larger for aqueous solutions since the solubility of cysteine in water is much higher compared to that in toluene. For the $\mathrm{CdSe}$ sensitized $\mathrm{TiO}_{2}$ films, the absorption band around $1589 \mathrm{~cm}^{-1}$ due to the COO-Ti groups as shown in curve (b) and curve (d) was overlapped with the absorption band around $1620 \mathrm{~cm}^{-1}$ which can be attributed to $\mathrm{H}_{2} \mathrm{O}$. On the other hand, the absorption bands around $2925 \mathrm{~cm}^{-1}$ and $2857 \mathrm{~cm}^{-1}$ were attributed to the vibration mode of $-\mathrm{CH}_{3}$ groups of fatty acids (oleic acids and myristic acids coming from the QD preparation and

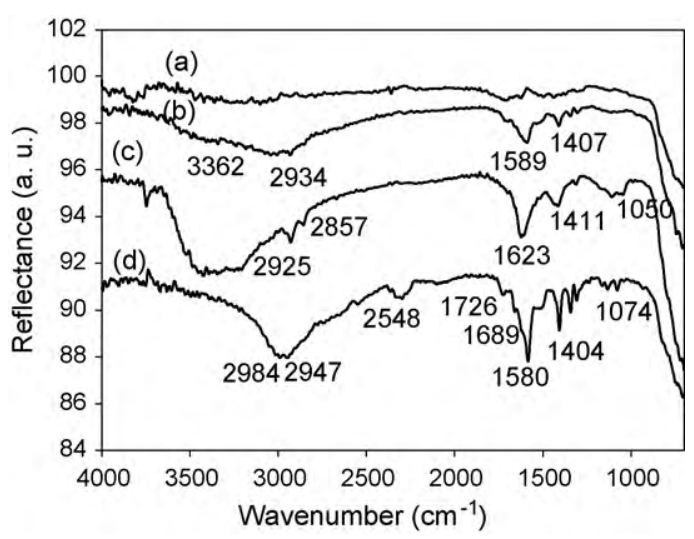

Fig. 2. The ATR-FTIR spectra of (a) the $\mathrm{TiO}_{2}$ films, (b) the cysteine coated $\mathrm{TiO}_{2}$ films for the toluene solution, (c) the CdSe sensitized $\mathrm{TiO}_{2}$ films (cysteine in toluene solution was used), and (d) the cysteine coated $\mathrm{TiO}_{2}$ films for the aqueous solution. 
Table 2

The vibration band assignments of the ATR-IR spectra for the $\mathrm{TiO}_{2}$ films coated with cysteine and CdSe QDs.

\begin{tabular}{|c|c|c|c|c|}
\hline & & $\begin{array}{l}\mathrm{TiO}_{2} / \text { Cys. } \\
\text { toluene }\end{array}$ & $\begin{array}{l}\mathrm{TiO}_{2} / \text { Cys./ } \\
\text { QDs }\end{array}$ & $\begin{array}{l}\mathrm{TiO}_{2} / \text { Cys. } \\
\text { water }\end{array}$ \\
\hline \multirow[t]{3}{*}{$-\mathrm{NH}_{2}$} & $v_{\mathrm{s}} \mathrm{N}-\mathrm{H} / \mathrm{cm}^{-1}$ & 3362,2934 & 1 & 2947 \\
\hline & $\delta_{\mathrm{as}} \mathrm{NH}_{3}^{+} / \mathrm{cm}^{-1}$ & 1695 & I & 1689 \\
\hline & $\delta_{\mathrm{s}} \mathrm{NH}_{3}^{+} / \mathrm{cm}^{-1}$ & 1532 & I & 1520 \\
\hline \multirow[t]{2}{*}{$-\mathrm{CH}_{3}$} & $v_{\mathrm{as}} \mathrm{CH}_{3} / \mathrm{cm}^{-1}$ & 1 & 2925 & 1 \\
\hline & $v_{\mathrm{s}} \mathrm{CH}_{3} / \mathrm{cm}^{-1}$ & I & 2857 & 1 \\
\hline$-\mathrm{SH}$ & $v \mathrm{~S}-\mathrm{H} / \mathrm{cm}^{-1}$ & & & 2548 \\
\hline \multirow[t]{2}{*}{-COOM } & $v_{\mathrm{s}} \mathrm{O}=\mathrm{C}=\mathrm{O} / \mathrm{cm}^{-1}$ & 1589 & 1590,1620 & 1580 \\
\hline & $v_{\text {as }} \mathrm{O}=\mathrm{C}=\mathrm{O} / \mathrm{cm}^{-1}$ & 1407 & 1411 & 1404 \\
\hline \multirow[t]{2}{*}{$-\mathrm{COOH}$} & $v \mathrm{C}=\mathrm{O} / \mathrm{cm}^{-1}$ & 1 & I & 1726 \\
\hline & $v 0-\mathrm{H} / \mathrm{cm}^{-1}$ & 1 & 1 & 2984 \\
\hline $\mathrm{C}-\mathrm{NH}_{2}$ & $\nu \mathrm{C}-\mathrm{N} / \mathrm{cm}^{-1}$ & 1080 & 1050 & 1074 \\
\hline
\end{tabular}

Table 3

Photovoltaic parameters of the QDSSCs for both cysteine solutions.

\begin{tabular}{lllll}
\hline Solvent & $V_{\text {oc }}(\mathrm{V})$ & $J_{\mathrm{sc}}\left(\mathrm{mAcm}^{-2}\right)$ & FF & $\eta(\%)$ \\
\hline Toluene & 0.49 & 3.8 & 0.22 & 0.41 \\
$\mathrm{H}_{2} \mathrm{O}$ & 0.50 & 3.0 & 0.35 & 0.53 \\
\hline
\end{tabular}

attached to the QD surface) and TOP which was coated on the surface of CdSe QDs. All these phenomena suggested that most of the surface of the CdSe QDs was still covered with fatty acids and TOP, and just few of these molecules have been exchanged by cysteine. The adsorption band around $1695 \mathrm{~cm}^{-1}$ and $2934 \mathrm{~cm}^{-1}$ attributed to the $\mathrm{NH}^{3+}$ groups and the $\mathrm{N}-\mathrm{H}$ groups have disappeared, which suggested that the amina group in cysteine can interact with the slightly acidic surface of $\mathrm{TiO}_{2}$. This interaction can push closer QDs to $\mathrm{TiO}_{2}$ surface explaining the better results for QDSSCs obtained using cysteine as linker molecule in comparison with MPA and TGA [8].

Fig. 3 shows the photocurrent-voltage curves of the CdSe QDSSCs for both cysteine solutions. The photovoltaic parameters of the cells are shown in Table 3 . The $V_{\text {oc }}$ of both tested cells is almost identical. Conversely, $J_{\mathrm{sc}}$ was higher for the toluene solution in good

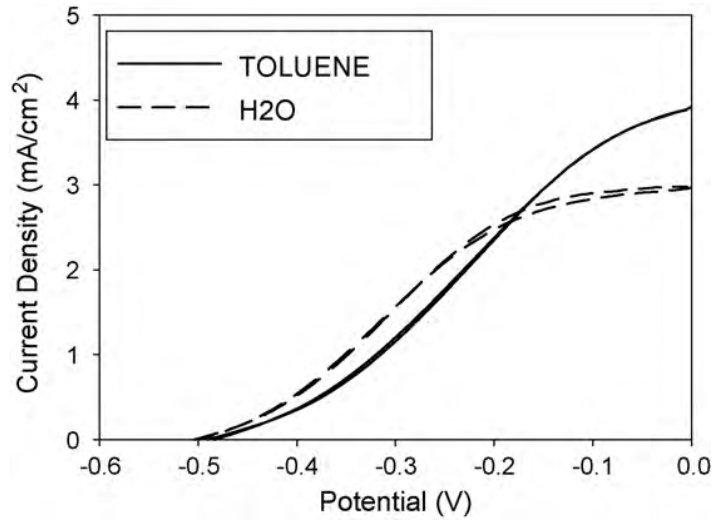

Fig. 3. The $j-V$ curves of the CdSe QDSSCs for both cysteine solutions.

correspondence with the results showed in Fig. 1. However, the fill factor was much higher for the water solution. This suggests that the large amount of adsorbed cysteine on $\mathrm{TiO}_{2}$ may reduce electron recombination at the interface between the $\mathrm{TiO}_{2}$ electrodes and electrolyte, leading to higher recombination resistance and higher fill factor [11].

Fig. 4a shows the open-circuit voltage decay (OCVD) curves for the CdSe QDSSCs for the different cysteine solutions. The electron lifetime $\tau$ can be derived from the OCVD curves as follows [12,13]:

$\tau=-\frac{k T}{e}\left(\frac{d V_{\mathrm{oc}}}{d t}\right)^{-1}$

where $k$ is the Boltzmann constant and $T$ is the absolute temperature. Fig. $4 \mathrm{~b}$ shows the electron lifetime determined from OCVD. The electron lifetime was higher for the water solution, indicating that the interfacial charge transfer has been suppressed by the cysteine molecules adsorbed on the $\mathrm{TiO}_{2}$ surface [14]. This perfectly agrees with the results showed in Fig. 3.

Fig. 5a shows the cyclic voltammetry (CV) curves of the CdSe QDSSCs for both cysteine solutions and Fig. 5b shows the total resis-
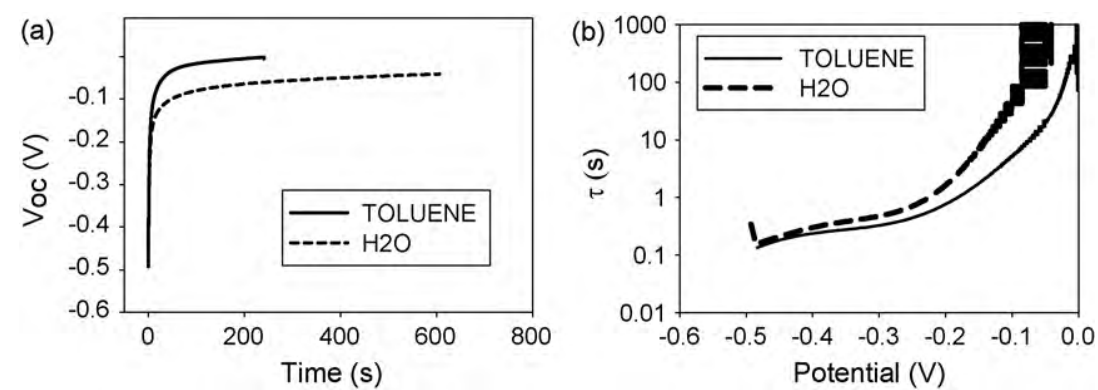

Fig. 4. The open-circuit voltage decay curves (a) of the CdSe QDSSCs and the electron lifetime (b) for the different cysteine solutions.
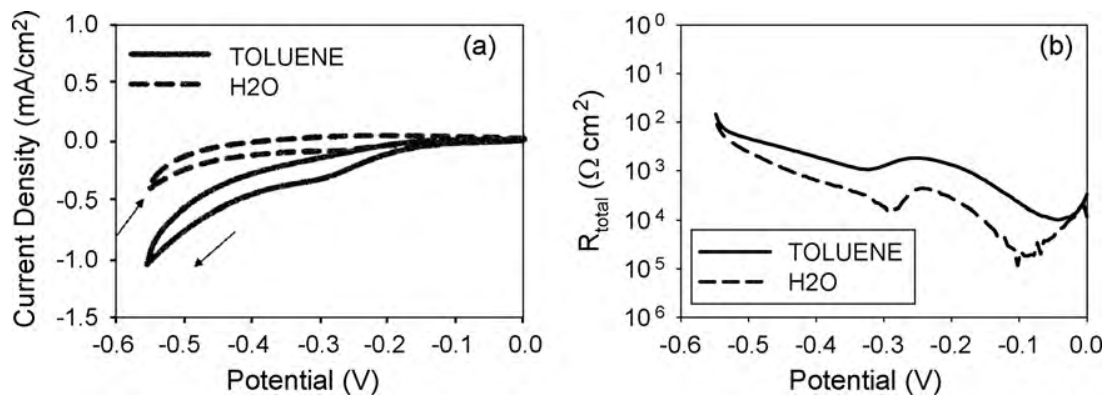

Fig. 5. The cyclic voltammetry curves (a) and the total resistance in dark (b) for the CdSe QDSSCs for both cysteine solutions. 
tance of the cells calculated from CV, averaging anodic and cathodic currents, according to following formula $[15,16]$ :

$R_{\mathrm{total}}=\frac{d V}{d i}$

The current in dark was smaller and the total resistance was larger for the water solution, indicating a lower electron recombination if the variation of the series resistance is ignored and assuming that the main contribution to the total resistance, $R_{\mathrm{total}}$, is the recombination resistance [11]. This agrees with the results from OCVD (Fig. 4) and the $j-V$ curve (Fig. 3 ). The small peak at $-0.3 \mathrm{~V}$ was attributed to surface states as it has been previously pointed out [11].

\section{Conclusions}

From the obtained experimental results, it is clear that the higher solubility of cysteine in water (compared with toluene), leads to a higher amount of adsorbed molecules onto the $\mathrm{TiO}_{2}$ substrates. The over-adsorption of cysteine on the surface of the $\mathrm{TiO}_{2}$ electrodes when the water solution is used, leads to a partial inhibition for the adsorption of CdSe QDs. These QDs do not completely substitute their surfactant molecules by cysteine as illustrated by the ATR-FTIR measurements. The photoelectrochemical behavior of the tested electrodes suggests that a large amount of cysteine on the surface of the $\mathrm{TiO}_{2}$ electrodes could reduce the electron recombination at the interface between the $\mathrm{TiO}_{2}$ electrodes and electrolytes, pointing out the importance of surface treatments in QD sensitized cells. On the other hand the amina group can interact with the slightly acidic surface of $\mathrm{TiO}_{2}$, reducing the distance between $\mathrm{QD}$ and $\mathrm{TiO}_{2}$, increasing the performance of QDSSCs when this linker is used.

\section{Acknowledgements}

The authors would like to acknowledge the financial support from the Study Aboard Project of Chinese Academy of Sciences in 2007, Ministerio de Educacion y Ciencia under project HOPE CSD2007-00007 (Consolider-Ingenio 2010) MAT2007-62982 and research contract RYC-2007-01381, and by Generalitat Valenciana project PROMETEO/2009/058, Preferred Foundation of Director of Guangzhou Institute of Energy Conversion of CAS in 2007, the Sci- ence and Technology Research Program of Guangdong Province (2008B010600047), and the National High Technology Research and Development Program of China (2007AA05Z431).

\section{References}

[1] B. 0'Regan, M. Grätzel, A low-cost, high-efficiency solar-cell based on dyesensitized colloidal $\mathrm{TiO}_{2}$ films, Nature 353 (1991) 737-740.

[2] J. Bisquert, Physical electrochemistry of nanostructured devices, Phys. Chem. Chem. Phys. 10 (1) (2008) 49-72.

[3] A.J. Nozik, Quantum dot solar cells, Physica E 14 (2002) 115-120.

[4] P. Wang, S.M. Zakeeruddin, J.E. Moser, et al., Stable new sensitizer with improved light harvesting for nanocrystalline dye-sensitized solar cells, Adv. Mater. 16 (2004) 1806

[5] R.D. Schaller, V.I. Klimov, High efficiency carrier multiplication in PbSe nanocrystals: implications for solar energy conversion, Phys. Rev. Lett. 92 (2004) 186601.

[6] A.J. Nozik, S. Tetsuo, Quantum Structured Solar Cells. Nanostructured Materials for Solar Energy Conversion, Elsevier, Amsterdam, 2006, p. 485.

[7] I. Robel, V. Subramanian, M. Kuno, P.V. Kamat, Quantum dot solar cells. Harvesting light energy with CdSe nanocrystals molecularly linked to mesoscopic $\mathrm{TiO}_{2}$ films, J. Am. Chem. Soc. 128 (2006) 2385.

[8] I. Mora-Seró, S. Giménez, T. Moehl, F. Fabregat-Santiago, T. Lana-Villareal, R. Gómez, J. Bisquert, Factors determining the photovoltaic performance of a CdSe quantum dot sensitized solar cell: the role of the linker molecule and of the counter electrode, J. Nanotechnol. 19 (2008) 424007.

[9] Q. Wang, D. Pan, S. Jiang, X. Ji, L. An, B. Jiang, A solvothermal route to size- and shape-controlled CdSe and CdTe nanocrystals, J. Cryst. Growth 286 (2006) 83

[10] F. Huang, G. Chen, Preparation and application of L-cysteine-modified CdSe/CdS core/shell nanocrystals as a novel fluorescence probe for detection of nucleic acid, Spectrochim. Acta Part A: Mol. Biomol. Spectrosc. 70 (2008) 318-323.

[11] I. Mora-Seró, S. Giménez, F. Fabregat-Santiago, R. Gómez, Q. Shen, T. Toyoda, J Bisquert, Recombination in quantum dot sensitized solar cells, Acc. Chem. Res. 42 (11) (2009) 1848-1857.

[12] A. Zaban, M. Greenshtein, J. Bisquert, Determination of the electron lifetime in nanocrystalline dye solar cells by open-circuit voltage decay measurements, Chem. Phys. Chem. 4 (2003) 859-864.

[13] J. Bisquert, A. Zaban, M. Greenshtein, I. Mora-Seró, Determination of rate constants for charge transfer and the distribution of semiconductor and electrolyte electronic energy levels in dye-sensitized solar cells by open-circuit photovoltage decay method, J. Am. Chem. Soc. 126 (2004) 13550-13559.

[14] F. Fabregat-Santiago, J. Garcia-Canadas, E. Palomares, J.N. Clifford, S.A. Haque J.R. Durrant, G. Garcia-Belmonte, J. Bisquert, The origin of slow electron recombination processes in dye-sensitized solar cells with alumina barrier coatings, J. Appl. Phys. 96 (2004) 6903-6907.

[15] F. Fabregat-Santiago, J. Bisquert, E. Palomares, L. Otero, D. Kuang, S.M. Zakeeruddin, M. Grätzel, Correlation between photovoltaic performance and impedance spectroscopy of dye-sensitized solar cells based on ionic liquids, J. Phys. Chem. C 111 (2007) 6550

[16] Q. Wang, S. Ito, M. Grätze, F. Fabregat-Santiago, I. Mora-Seró, J. Bisquert, T. Bessho, H. Imai, Characteristics of high efficiency dye-sensitized solar cells, J. Phys. Chem. B 110 (2006) 25210-25221. 